\title{
Implementation of a Care Manager Organization and Its Association with Health Care Contacts and Psychotherapy: A Register-Based Study of Real-Life Outcomes at Primary Health Care Centers in Sweden
}

\author{
Christine Sandheimer (D) \\ Cecilia Björkelund ${ }^{2,3}$ \\ Gunnel Hensing' \\ Tove Hedenrud ${ }^{4}$ \\ 'Social Medicine, School of Public Health \\ and Community Medicine, Institute of \\ Medicine, The Sahlgenska Academy, \\ University of Gothenburg, Gothenburg, \\ Sweden; ${ }^{2}$ Primary Health Care, School of \\ Public Health and Community Medicine, \\ Institute of Medicine, The Sahlgenska \\ Academy, University of Gothenburg, \\ Gothenburg, Sweden; ${ }^{3}$ Research and \\ Development, Primary Health Care, \\ Region Västra Götaland, Sweden; \\ ${ }^{4}$ Medicine Use \& Pharmaceutical Policy, \\ School of Public Health and Community \\ Medicine, Institute of Medicine, The \\ Sahlgenska Academy, University of \\ Gothenburg, Gothenburg, Sweden
}

Correspondence: Christine Sandheimer Tel +46766186874

Email Christine.sandheimer@gu.se
Background: A care manager organization, based on a collaborative care model, was implemented in the primary health care service in Region Västra Götaland, Sweden, to improve the care of persons with common mental disorders (CMDs). We aimed to investigate the association between the care manager organization and number of health care contacts, and the extent of psychotherapy among female and male patients with CMD compared to primary health care centers (PHCCs) offering usual care, in the introductory year of implementation with one year follow-up.

Methods: This register-based study included all PHCCs in the region, which were analyzed in two groups depending on their care manager status. The study periods were 2015.09.012016.08.31 (first year) and 2016.09.01-2017.08.31 (second year). Data on health care contacts and psychotherapy per PHCC were obtained from a health care register. The mean number and proportion of visits to different health care professionals, and the proportion of patients with shortterm versus long-term psychotherapy were measured. A linear mixed-effects model for crosssectional and longitudinal analysis was implemented as well as a generalized linear regression model for possible interaction effects of PHCC characteristic on care manager status and outcomes. Results: PHCCs with a care manager organization had more nurse contacts $(\mathrm{p}=0.001$ for both year 1 and year 2) compared to PHCCs with usual care. PHCCs with usual care had a significantly lower proportion of visits to psychotherapists and a higher proportion of both female and male patients receiving short-term psychotherapy ( $1-5$ sessions vs $\geq 6$ ) over time and compared to PHCCs with a care manager organization.

Conclusion: With a care manager organization, nurse contacts increased at the PHCCs. However, this did not negatively influence the visits to a general practitioner and to psychotherapists. This evaluation showed that the care manager organization at PHCC level implies higher accessibility and sustainability of care for up to two years after implementation.

Keywords: care manager, collaborative care, health services research, psychological treatment, primary care

\section{Introduction}

In recent years, depression, anxiety syndromes, and stress-related mental disorder, also known as common mental disorders (CMDs), have represented an increasing and significant part of the disease burden in the majority of the EU countries, the 
United Kingdom and the United States. ${ }^{1}$ Furthermore, almost one in five members of the working-age population in these countries are affected annually. ${ }^{2}$ To suffer from CMD usually affects both physical and mental capacities which, if left untreated, can lead to an increased risk of a prolonged state of illness and future sick leave. ${ }^{3}$

Both women and men with CMD seek and receive care from the primary health care service, ${ }^{4,5}$ although men have been shown not to seek mental health care, nor to perceive the care as sufficient, to the same extent as women. ${ }^{6}$ Common care measures for CMDs in the primary health care service include six or more sessions of psychotherapy (such as Cognitive Behavioral Therapy "CBT" or Interpersonal Therapy "IPT") and/or at least six months of medication therapy with antidepressants (eg predominantly Selective serotonin reuptake inhibitors "SSRIs" or Serotonin-noradrenaline reuptake inhibitors "SNRIs"). $3,7,8$ However, the evidence of the treatments' effectiveness among the patient group is ambiguous, ${ }^{9}$ especially when the psychotherapy or medication therapy was given as single measures without support or monitoring by the treating health care provider. $^{10,11}$ In the Swedish National Guidelines, high accessibility and continuity of care in primary health care is highly ranked for this group of patients, and from 2017, new recommendations for collaborative care with a care manager were introduced to improve care and to increase the sustainability and effectiveness of care for patients with CMD. ${ }^{3}$

Collaborative care models are complex organizational interventions that include a multi-professional approach with a care manager (often a specially trained nurse) who has the responsibility to set up a person-centered care plan with the patient with diagnosed CMD, to give regular follow-up sessions, and to work in close collaboration with the treating general practitioner (GP). ${ }^{12,13}$

In Swedish primary health care, the presence of staff with various competences at the primary health care center (PHCC) is common. Besides GPs and specialized nurses, also psychotherapists, physiotherapists and counsellors work part- or full-time. ${ }^{14}$ However, team-based care is not always available and access to both GPs and psychotherapists does not always match the demand. ${ }^{15}$

The Region Västra Götaland, a geographical and political entity responsible for the financing, organization, and production of the regional health care service, ${ }^{16}$ located in southwest Sweden, started implementing a collaborative care model with a care manager (hereafter called the care manager organization) in 2015 . The decision by the region to implement a care manager organization was based on the findings and experiences from a randomized controlled trial (RCT) where the care manager function was tested in 23 PHCCs in Region Västra Götaland in 2014 (more information about the RCT and the implementation process can be found in other publications ${ }^{17,18}$ ). In the implementation of a care manager organization, one of the objectives is to establish local team collaboration at the PHCC. The added value of a care manager organization at the PHCC represents an enhancement of accessibility and continuity of care as well as person-centered care ${ }^{19}$ with additional allocation of regional reimbursements to compensate for increased costs of care and staffing. The implementation is still ongoing, and today (fall 2021) almost 175 of the approximately 200 PHCCs in the region have established a care manager organization.

Since the care manager organization in the Swedish primary health care service is new and relatively unexplored the main objective of this study was to investigate the implementation of the care manager organization in Region Västra Götaland in the introductory year of the implementation and in the second year when the new working routines should have become settled in the ordinary practice of the PHCCs. To our knowledge, no prior studies have investigated the effects of the collaborative care model on an organizational level except for our previous study where we showed a positive association between PHCCs with a care manager organization and antidepressant medication patterns during the first year of implementation. ${ }^{18}$ In this present study, we focus on health care contacts and psychotherapy patterns, since the main task for the care manager is to help the patient with CMD to carry out and complete treatment. One objective of the care manager organization is to act as a "door-opener" to evidence-based and continuous care for patients with CMD.

Hence, we aimed to investigate the association between the care manager organization and number of health care contacts and extent of psychotherapy compared to usual care (ie, PHCCs without a care manager organization) during the introductory year of implementation with one year follow-up after establishment. Furthermore, we investigated whether differences in outcomes could be seen among both a female and male patient population. 


\section{Materials and Methods}

\section{Study Design and Research Setting}

The present study used aggregated register data at PHCC level and was conducted in the primary health care service in Region Västra Götaland, the second largest of Sweden's 21 regions, with 1.7 million inhabitants (approximately $17 \%$ of the Swedish population). The study was a collaboration between the research programme "New Ways - mental health at work" and the research project PRIM-CARE (PRIMary care CARE manager) in the research platform "Ways-of-life, stress and mental health in the primary care context", both at the School of Public Health and Community Medicine, University of Gothenburg, Sweden, in cooperation with the department Research and Development Primary Health care at Region Västra Götaland.

\section{Participating PHCCs and Study Periods}

We included all PHCCs in Region Västra Götaland, with the exception of outpatient primary emergency care centers that are only active when the regular PHCCs are closed (during evenings and weekends). The study periods of interest were 1) 1st of September 2015, when the implementation process started in the region, to 31 st of August 2016 (hereafter referred to as the introductory phase), and 2) 1st of September 2016 to 31st of August 2017 when the new organization with changed clinical routines had been ongoing for more than one year (hereafter referred to as the establishment phase).

The PHCCs were divided into two groups based on their care manager status (measured by the registration of a specific care manager code): (i) PHCCs with an established care manager organization during the whole study period, (ii) PHCCs which had not implemented a care manager organization within the study period (ie, usual care).

\section{Study Population and Outcomes}

The patient populations of interest were women and men with a CMD diagnosis, 18 years and older that received care at a PHCC in the region within the study periods. A CMD diagnosis included the following diagnoses according to the International Statistical Classification of Diseases and Related Health Problems (ICD) 10: depression (F32, F33), anxiety syndromes (F40, F41), and/or stress-related mental disorders (F43, including acute stress reaction, adjustment disorder, and exhaustion disorder).
For the outcome "health care contacts", we used two different measures: (1) mean number of visits to i) psychotherapist, ii) GP, and iii) nurse, by the patient population; and (2) mean proportion of visits to i) psychotherapist, ii) GP, and iii) nurse, of total visits to the PHCC by the patient population.

The mean number of visits per PHCC was calculated for each health care professional with the following equation:

$$
\begin{aligned}
& \frac{\text { No. of visits to }(\mathrm{GP})}{\text { No. of patients with CMD at the PHCC }}=\text { Mean no. of } \\
& \text { visits to }(\mathrm{GP}) \text { by the patient population }
\end{aligned}
$$

The mean proportion of visits per PHCC was calculated for each health care professional with the following equation:

$$
\begin{aligned}
& \frac{\text { No. of visits to }(\mathrm{GP})}{\text { No. of visits to }(\mathrm{GP}+\text { Nurse }+ \text { Psychotherapist }+ \text { Other })}=\text { Mean } \\
& \text { proportion of visits to }(\mathrm{GP}) \text { per PHCC }
\end{aligned}
$$

For the outcome "extent of psychotherapy", we used the measure mean proportion of patients with a CMD diagnosis receiving short-term (one to five sessions) versus long-term ( $\geq 6$ sessions) psychotherapy from the total received psychotherapy (at least one session) at the PHCC. The mean proportion of psychotherapy per PHCC was calculated for short-term and long-term psychotherapy respectively with the following equation:

$$
\begin{aligned}
& \text { No. of patients with psychotherapy (Short) } \\
& \text { proportion of (short term) psychotherapy }
\end{aligned}
$$

Proportions were calculated for each outcome to minimize the effect of large variations in PHCC size.

\section{Register Data}

Data on health care contacts and psychotherapy were obtained from the VEGA health care database. VEGA contains information about all health care contacts and received care measures for the region's inhabitants and is actively managed by regional officials at the Department of Data and Analysis at Region Västra Götaland. All PHCCs in the region are obliged to send in their information to VEGA and the database is updated systematically every month. Additional information about background characteristics of the included PHCC, such as ownership (public or private), PHCC size (number of listed patients per PHCC) and location, was also collected. The included register data contained information on PHCC level and 
was therefore aggregated with no possibility to identify any individual patient. Ethical permission to extract data from VEGA was obtained from the Regional Ethical Review Board in Gothenburg, Sweden (Dnr: T566-17).

\section{Statistical Analysis}

Descriptive statistics of the PHCCs' characteristic, with group differences according to care manager status, were assessed with the non-parametric independent samples Mann-Whitney $U$-test and presented with $p$-values. A linear mixed-effects model was applied to investigate both cross-sectional effects and longitudinal changes in the proportion of visits to different health care professionals and the proportion of patients with short-term or long-term psychotherapy, among a female and male patient population. The model takes into consideration potential correlations between and within PHCC groups by using repeated measures (PROC MIXED function in the statistical software SAS). ${ }^{20}$ The linear mixed-effects model included care manager status ( $\mathrm{ref}=$ usual care), the two time periods (ie, 2015-2016 and 2016-2017), and the interaction between care manager status and time periods. The results of the analysis are presented in mean percent with confidence intervals (CI).

Additional interaction effects analysis was conducted by using a generalized linear regression model (PROC GLM function in SAS) to measure potential associations between the outcome variables and care manager status with the descriptive variables PHCC size and PHCC status (public or private ownership).

Analyses were conducted with IBM SPSS Statistics ${ }^{\circledR}$ version 27 and SAS version 9.4 (SAS Institute, Cary, NC). The significance level was set at 0.05 with $95 \%$ CI.

\section{Results}

The total sample of included PHCCs was 215. This figure comprised 81 PHCCs that had a care manager organization during both time periods and 134 PHCCs that had not implemented the organization within the study period (usual care). Table 1 presents the descriptive statistics of the PHCCs according to their care manager status. The result from the descriptive analysis showed that PHCCs with usual care to a greater extent had private management compared to PHCCs with a care manager organization $(55 \%$ vs $35 \%, \mathrm{p}=0.003)$. The analysis of interaction effects on all outcome variables (health care contacts and extent of psychotherapy) with care manager status and PHCC status showed no statistical significance (data not shown), meaning that the association between care manager status and measured outcomes did not differ between private or public PHCCs. Overall, the 81 PHCCs with a care manager organization were larger, with more listed patients per PHCC than the PHCCs with usual care $(p=0.004$ year 1 , and $p=0.01$ year 2$)$. The interaction effect analysis showed that the PHCC size was associated with care manager status and type of ownership $(p=0.003)$. No other interaction effects between PHCC size and the different outcome variables on health care contacts and short- or long-term psychotherapy were shown ( $p>0.05$ for all outcomes).

The mean number of visits by patients with CMD to either a psychotherapist or to a GP did not differ between the two PHCC groups in either time period. The mean number of visits to nurses by the patient population was significantly higher in both time periods among PHCCs with a care manager organization compared to PHCCs without ( $p=0.001$ for both year 1 and year 2 ). The significant difference in visits to a nurse between the two PHCC groups was larger among the male population in year 2 compared to year 1 (from $p=0.03$ to $p=0.002$ ).

\section{The Proportion of Health Care Contacts}

The results from the cross-sectional analysis showed no statistically significant differences between PHCCs with and without a care manager organization as regards the proportion of visits to a psychotherapist (Table 2). Statistically significant differences between PHCC groups were shown in the proportion of visits to a nurse and to a GP, among both female and male patients with a CMD diagnosis. The largest difference in the proportion of visits to a nurse was seen in the male patient population the second year after implementation, with PHCCs with a care manager organization having a $3.7 \%$ (CI 1.1; 6.2) higher proportion of visits compared to PHCCs with usual care $(27.7 \%$ versus $24 \%)$. In the proportion of visits to a GP, the largest difference between the PHCC groups was shown in the male patient population with a difference of $+3.4 \%$ (CI $-6.0 ;-0.7)$ in PHCCs with usual care in year two $(55.3 \%$ versus $51.9 \%$ in PHCCs with the care manager organization).

The longitudinal analysis showed that only PHCCs with usual care had a significantly lower proportion of visits to psychotherapists among both the female and male patient population from year one to year two. The increase in the proportion of visits to a nurse by the female patient population was statistically significant in both PHCC groups. In the male population, the increase in the proportion of visits to a nurse was only significant in PHCCs with a care manager organization (from $25.7 \%$ to $27.7 \%$, CI $0.5 ; 3.6$ ). 
Table I Descriptive Statistics of PHCCs by Care Manager Status $\left(\mathrm{CAU}^{+}, \mathrm{CMO}^{++}\right)$at Year I (September 2015-August 2016) and Year 2 (September 2016 - August 2017)

\begin{tabular}{|c|c|c|c|c|c|c|}
\hline & \multicolumn{3}{|c|}{ Introductory Phase (Year I) } & \multicolumn{3}{|c|}{ Establishment Phase (Year 2) } \\
\hline & CAU & CMO & & CAU & CMO & \\
\hline & n (\%) & n (\%) & $\mathbf{P}$ & n (\%) & n (\%) & $\mathbf{P}$ \\
\hline \multicolumn{7}{|l|}{ PHCC status } \\
\hline Public & $60(45)$ & $53(65)$ & $0.003 * *$ & $60(45)$ & $53(65)$ & $0.003^{* *}$ \\
\hline Private & $74(55)$ & $28(35)$ & & $74(55)$ & $28(35)$ & \\
\hline \multicolumn{7}{|l|}{ Geographical location $^{\mathrm{a}}$} \\
\hline Urban & 117 (87) & $69(85)$ & 0.66 & II 6 (87) & $69(85)$ & 0.78 \\
\hline Rural & $17(13)$ & $12(15)$ & & $18(13)$ & $12(15)$ & \\
\hline PHCCs with no. of listed patients & & & $0.004 * *$ & & & $0.01 *$ \\
\hline$<5000$ & $35(29)$ & II (14) & & $33(28)$ & $11(14)$ & \\
\hline $5000-<7000$ & $20(17)$ & $9(11)$ & & $21(18)$ & II (14) & \\
\hline $7000-<10.000$ & $34(29)$ & $32(40)$ & & $35(29)$ & $30(37)$ & \\
\hline$\geq 10.000$ & $30(25)$ & $29(36)$ & & $31(26)$ & $29(36)$ & \\
\hline Median (min-max) & $744 \mid(252-20,219)$ & $9020(2390-1894)$ & & $781 \mid(503-19,210)$ & $8932(2667-18,504)$ & \\
\hline $\begin{array}{l}\text { Proportion of patients with CMD } \\
\text { diagnosis per } \mathrm{PHCC}^{\mathrm{b}} \text {, }\end{array}$ & $\%$ (SD) & $\%(\mathrm{SD})$ & & $\%(\mathrm{SD})$ & $\%$ (SD) & \\
\hline Women & $11.9(4.3)$ & $11.9(2.4)$ & 0.40 & I2.7 (4.7) & $12.5(2.5)$ & 0.41 \\
\hline Men & $5.7(2.2)$ & $5.7(1.2)$ & 0.25 & $6.0(2.7)$ & $6.0(1.4)$ & 0.33 \\
\hline Total & $8.8(3.2)$ & $8.8(1.8)$ & 0.33 & $9.3(3.5)$ & $9.3(2.0)$ & 0.38 \\
\hline $\begin{array}{l}\text { Mean no. of visits by patients with } \\
\text { CMD toc: }\end{array}$ & Mean (SD) & Mean (SD) & & Mean (SD) & Mean (SD) & \\
\hline \multicolumn{7}{|l|}{ Psychotherapist } \\
\hline Women & $0.79(0.60)$ & $0.66(0.46)$ & 0.32 & $0.62(0.43)$ & $0.63(0.45)$ & 0.89 \\
\hline Men & $0.69(0.49)$ & $0.62(0.40)$ & 0.65 & $0.56(0.39)$ & $0.56(0.40)$ & 0.92 \\
\hline Total & $0.75(0.54)$ & $0.64(0.43)$ & 0.31 & $0.59(0.40)$ & $0.60(0.43)$ & 0.91 \\
\hline \multicolumn{7}{|l|}{ Nurse } \\
\hline Women & $0.93(0.60)$ & I.34 (0.49) & $0.000 * * *$ & I.0I (0.65) & $1.39(0.49)$ & $0.001 * * *$ \\
\hline Men & $1.0(0.65)$ & $1.40(0.65)$ & $0.03 *$ & $1.06(0.69)$ & $1.46(0.58)$ & $0.002 * * *$ \\
\hline Total & $0.95(0.59)$ & $1.36(0.52)$ & $0.001 * * *$ & $1.03(0.64)$ & $1.42(0.50)$ & $0.001 * * *$ \\
\hline \multicolumn{7}{|l|}{ GP } \\
\hline Women & $3.0(0.66)$ & $3.0(0.44)$ & 0.84 & $2.93(0.58)$ & $2.97(0.45)$ & 0.70 \\
\hline Men & $2.70(0.60)$ & $2.69(0.42)$ & 0.54 & $2.68(0.57)$ & $2.68(0.4 I)$ & 0.92 \\
\hline Total & $2.87(0.62)$ & $2.90(0.42)$ & 0.94 & $2.85(0.57)$ & $2.88(0.42)$ & 0.76 \\
\hline
\end{tabular}

Notes: a Measured by whether the PHCCs had received earmarked reimbursement for their geographical location (ie distant location from large city or hospital, location on an island without bridge connection, et cetera.) during the study period. ${ }^{b}$ Proportion calculated by dividing number of patients with CMD with number of listed patients at each PHCC group. 'Mean number calculated by dividing number of visits for eg GP by patients with CMD with number of patients with CMD at each PHCC group. *P-value of $<0.05$. **P-value of $<0.01$. ***P-value of $<0.00$ I.

Abbreviations: ${ }^{+} \mathrm{CAU}$, care as usual; ${ }^{++} \mathrm{CMO}$, care manager organization.

\section{Extent of Psychotherapy}

The cross-sectional results showed a significant difference between PHCCs with and without a care manager organization in the proportion of short-term psychotherapy in both the female and male patient population in year 2 (Table 3). The proportion of short-term psychotherapy among female patients was $4.9 \%(\mathrm{CI}-8.7 ;-1.1)$ lower in PHCCs with a care manager organization compared to PHCCs with usual care $(75.3 \%$ versus $80.2 \%)$. The proportion of male patients receiving short-term psychotherapy was $4.6 \%$ (CI -8.7 ; -0.5$)$ lower for PHCCs with a care manager organization in comparison with PHCCs without $(77.8 \%$ versus $82.4 \%)$. No statistically significant differences were seen between the two PHCC groups in 
Table 2 Cross-Sectional and Longitudinal Comparisons of Mean Proportion of Health Care Contacts by Care Manager Status $\left(\mathrm{CAU}^{+}, \mathrm{CMO}^{++}\right)$at Year I (September 2015 - August 2016) and at Year 2 (September 2016 - August 2017), and from Year I to Year 2

\begin{tabular}{|c|c|c|c|}
\hline $\begin{array}{l}\text { PHCCs with Proportion } \\
\text { of Visits by Patients with } \\
\text { CMD to: }\end{array}$ & $\begin{array}{c}\text { CAU } \\
\text { Mean \% }\end{array}$ & $\begin{array}{c}\text { CMO } \\
\text { Mean \% }\end{array}$ & $\begin{array}{c}\text { Cl}^{\wedge} \\
\text { Between } \\
\text { Groups }\end{array}$ \\
\hline \multicolumn{4}{|l|}{ Psychotherapist } \\
\hline $\begin{array}{l}\text { Women } \\
\text { Year I } \\
\text { Year } 2 \\
\mathrm{Cl}^{\wedge} \text { within groups }\left(\mathrm{DF}^{\S}\right)\end{array}$ & $\begin{array}{c}13.5 \\
11.4 \\
-3.4 ;-0.8^{* *}\end{array}$ & $\begin{array}{c}11.9 \\
11.6 \\
-1.8 ; 1.2\end{array}$ & $\begin{array}{c}-4.3 ; 1.1 \\
-2.1 ; 2.4 \\
(180)\end{array}$ \\
\hline $\begin{array}{l}\text { Men } \\
\text { Year I } \\
\text { Year } 2 \\
\mathrm{Cl}^{\wedge} \text { within groups }\left(\mathrm{DF}^{\S}\right)\end{array}$ & $\begin{array}{c}12.9 \\
11.2 \\
-3.1 ;-0.2^{*}\end{array}$ & $\begin{array}{c}12.1 \\
11.1 \\
-2.7 ; 0.6\end{array}$ & $\begin{array}{c}-3.3 ; 1.8 \\
-2.2 ; 2.0 \\
(178)\end{array}$ \\
\hline Nurse & & & \\
\hline $\begin{array}{l}\text { Women } \\
\text { Year I } \\
\text { Year } 2 \\
\mathrm{Cl}^{\wedge} \text { within groups }\left(\mathrm{DF}^{\S}\right)\end{array}$ & $\begin{array}{c}20.6 \\
22.0 \\
0.4 ; 2.4^{* *}\end{array}$ & $\begin{array}{c}23.5 \\
24.7 \\
0.03 ; 2.4^{*}\end{array}$ & $\begin{array}{c}0.8 ; 5.1^{* *} \\
0.5 ; 5.0^{*} \\
(180)\end{array}$ \\
\hline $\begin{array}{l}\text { Men } \\
\text { Year I } \\
\text { Year } 2 \\
\mathrm{Cl}^{\wedge} \text { within groups }\left(\mathrm{DF}^{\S}\right)\end{array}$ & $\begin{array}{c}23.5 \\
24.0 \\
-0.8 ; 1.9\end{array}$ & $\begin{array}{c}25.7 \\
27.7 \\
0.5 ; 3.6 * *\end{array}$ & $\begin{array}{c}-0.1 ; 4.6 \\
I .1 ; 6.2^{* *} \\
(I 78)\end{array}$ \\
\hline GP & & & \\
\hline $\begin{array}{l}\text { Women } \\
\text { Year I } \\
\text { Year } 2 \\
\mathrm{Cl}^{\wedge} \text { within groups }\left(\mathrm{DF}^{\S}\right)\end{array}$ & $\begin{array}{c}56.4 \\
56.6 \\
-I .0 ; 1.4\end{array}$ & $\begin{array}{c}54.9 \\
54.0 \\
-2.3 ; 0.5\end{array}$ & $\begin{array}{c}-4.1 ; 1.0 \\
-5.3 ;-0.1^{*} \\
(180)\end{array}$ \\
\hline $\begin{array}{l}\text { Men } \\
\text { Year I } \\
\text { Year } 2 \\
\mathrm{Cl}^{\wedge} \text { within groups }\left(\mathrm{DF}^{\S}\right)\end{array}$ & $\begin{array}{c}55.2 \\
55.3 \\
-1.2 ; 1.4\end{array}$ & $\begin{array}{c}53.3 \\
51.9 \\
-2.9 ; 0.2\end{array}$ & $\begin{array}{c}-4.6 ; 0.8 \\
-6.0 ;-0.7 * * \\
(178)\end{array}$ \\
\hline
\end{tabular}

Notes: *P-value of $<0.05$. **P-value of $<0.01$.

Abbreviations: ${ }^{+} \mathrm{CAU}$, care as usual; ${ }^{++} \mathrm{CMO}$, care manager organization; ${ }^{\wedge} \mathrm{Cl}$, confidence intervals; ${ }^{\S} \mathrm{DF}$, degrees of freedom $(n-\mathrm{I})$.

the proportion of received long-term psychotherapy in either the female or the male patient population.

The longitudinal analysis of the proportion of female and male patients with CMD receiving short-term psychotherapy only showed statistically significant differences over time in PHCCs with usual care $(+4.9 \%$ for women, CI $2.5 ; 7.3$, and $+3.7 \%$ for men, CI $0.7 ; 6.6$ ). PHCCs with usual care had a significantly lower proportion of female patients receiving long-term psychotherapy in the second period compared to the first $(-5.8 \%, \mathrm{CI}-8.7 ;-2.8)$. No significant longitudinal
Table 3 Cross-Sectional and Longitudinal Comparisons of Mean Proportion of Length of Psychotherapy by Care Manager Status $\left(\mathrm{CAU}^{+}, \mathrm{CMO}^{++}\right)$at Year I (September 2015 - August 2016) and at Year 2 (September 2016 - August 2017), and from Year I to Year 2

\begin{tabular}{|c|c|c|c|}
\hline $\begin{array}{l}\text { PHCCs with Proportion } \\
\text { of Patients with CMD } \\
\text { Receiving: }\end{array}$ & $\begin{array}{c}\text { CAU } \\
\text { Mean \% }\end{array}$ & $\begin{array}{c}\text { CMO } \\
\text { Mean \% }\end{array}$ & $\begin{array}{c}\text { Cl^}^{\wedge} \\
\text { Between } \\
\text { Groups }\end{array}$ \\
\hline \multicolumn{4}{|c|}{ Short-term psychotherapy ( $1-5$ sessions) } \\
\hline \multicolumn{4}{|l|}{ Women } \\
\hline Year I & 75.3 & 75.7 & $-3.6 ; 4.4$ \\
\hline Year 2 & 80.2 & 75.3 & $-8.7 ;-1.1^{* *}$ \\
\hline$C l^{\wedge}$ within groups $\left(\mathrm{DF}^{\S}\right)$ & $2.5 ; 7.3 * * *$ & $-3.2 ; 2.4$ & (203) \\
\hline \multicolumn{4}{|l|}{ Men } \\
\hline Year I & 78.7 & 79.8 & $-3.1 ; 5.2$ \\
\hline Year 2 & 82.4 & 77.8 & $-8.7 ;-0.5 *$ \\
\hline $\mathrm{Cl}^{\wedge}$ within groups $\left(\mathrm{DF}^{\S}\right)$ & $0.7 ; 6.6^{*}$ & $-5.4 ; 1.5$ & (203) \\
\hline \multicolumn{4}{|c|}{ Long-term psychotherapy ( $\geq 6$ sessions) } \\
\hline \multicolumn{4}{|l|}{ Women } \\
\hline Year 1 & 28.4 & 25.4 & $-7.3 ; 1.4$ \\
\hline Year 2 & 22.6 & 25.0 & $-1.3 ; 5.9$ \\
\hline $\mathrm{Cl}^{\wedge}$ within groups $\left(\mathrm{DF}^{\S}\right)$ & $-8.7 ;-2.8^{* * *}$ & $-3.9 ; 2.9$ & (191) \\
\hline \multicolumn{4}{|l|}{ Men } \\
\hline Year I & 24.0 & 22.6 & $-5.4 ; 2.6$ \\
\hline Year 2 & 22.4 & 22.7 & $-4.0 ; 4.7$ \\
\hline $\mathrm{Cl}^{\wedge}$ within groups $\left(\mathrm{DF}^{\S}\right)$ & $-4.6 ; 1.4$ & $-3.3 ; 3.6$ & (189) \\
\hline
\end{tabular}

Notes: *P-value of $<0.05$. **P-value of $<0.01$. ***P-value of $<0.001$.

Abbreviations: ${ }^{+} \mathrm{CAU}$, care as usual; ${ }^{++} \mathrm{CMO}$, care manager organization; ${ }^{\wedge} \mathrm{Cl}$, confidence intervals; ${ }^{\S} \mathrm{DF}$, degrees of freedom $(\mathrm{n}-\mathrm{I})$.

difference in long-term psychotherapy was seen in PHCCs with a care manager organization.

\section{Discussion}

This study has evaluated the first year of implementation of a collaborative care organization with a care manager in Swedish primary health care with one year follow-up after the organization should have become embedded in ordinary practice. Our study investigated the impact of the organizational change on regional level by including all PHCCs whereas most other studies performed follow-up studies on separate PHCCs on individual level. ${ }^{21-23}$ Moreover, we investigated possible associations with the number of health care contacts and the extent of psychotherapy.

The findings showed that the proportion of visits to psychotherapists by both female and male patients with CMD did not differ to any great extent between PHCCs with the care manager organization compared to the 
PHCCs with usual care. However, among the PHCCs with usual care the mean proportion of psychotherapist contacts decreased significantly from year one to year two.

Other findings showed that both the mean number of nurse contacts and the proportion of visits to a nurse were significantly higher at PHCCs with a care manager organization compared to PHCCs with usual care. Furthermore, this did not negatively influence the comparatively high number and proportion of visits to GPs, which was found at both PHCC groups. The increase in visits to a nurse among PHCCs with a care manager organization could be expected as care managers are nurses employed at the PHCC and the care manager visits were included in this number.

Earlier research has shown an increase of health care contacts with the introduction of a care manager organization, with resulting higher health care costs per patient for the PHCC. ${ }^{24}$ However, other studies have shown that the societal costs for each patient become lower as the duration of sickness (measured in depression-free days) is reduced and quality-adjusted life years (health) improve faster with the care manager program compared to usual care. $^{25,26}$ An increase in health care contacts should therefore not be seen as something unreservedly negative but rather as a shift in health care expenses that could increase long-term gains for the health care system as a whole.

Regarding the extent of psychotherapy, it was shown that PHCCs with a care manager organization, in the second year after implementation, provided a significantly lower proportion of psychotherapy with fewer than six sessions (ie, short-term psychotherapy) among both women and men with CMD compared to PHCCs with usual care. In PHCCs with usual care, the mean proportion of patients with short-term psychotherapy increased noticeably from year 1 to year 2 . No significant differences were seen between the PHCC groups in psychotherapy lasting six sessions or more. However, an exception was seen in PHCCs with usual care which had a decreased proportion of long-term psychotherapy by the female patient group over time.

The recommendations in the national clinical treatment guidelines are based on at least six sessions of psychotherapy to patients with CMD in order for the treatment to have an optimal effect on the treatment outcome. ${ }^{3,7}$ Other studies have reported effectiveness after $6-8 \operatorname{sessions}^{27}$ or even eight sessions versus 16 or more. ${ }^{28}$ Although our findings showed that less than six sessions was the most common extent of psychotherapy in both PHCC groups, we were able to detect a trend towards psychotherapy of longer duration in PHCCs with a care manager organization and an increase in psychotherapy of shorter duration among PHCCs with usual care. This could indicate that PHCCs with a care manager organization have somewhat better capacity to offer treatment which is in accordance with previous research and national guidelines compared to PHCCs offering usual care.

We could not detect any significant differences between the female and male patient population in visits to a psychotherapist or in the extent of psychotherapy in either PHCC group. We did, however, see a stronger increase in visits to a nurse by male patients with a CMD compared to the female patients in PHCCs with a care manager organization in the second year after implementation. This could imply that the support of a care manager lowers the threshold for care and treatment for male patients, who in previous research have been shown not to seek care despite perceiving a need for care, ${ }^{6}$ and not to commit to or believe in the helpfulness of psychotherapy ${ }^{27}$ to the same extent as women.

All in all, our findings showed that some differences could be seen between PHCCs with a care manager organization compared to PHCCs without the organization the first year of implementation, with more considerable and more statistically significant differences the second year after implementation. As a comparison, a three-year follow-up study ${ }^{21}$ showed continuous effect differences at one year, but no significant difference between intervention patients receiving collaborative care and control patients at three years. Another longterm follow-up showed remaining effects of a care manager organization three years after the study close. ${ }^{22}$ The lack of sustainable effects during follow-up is a common problem in intervention studies. ${ }^{29}$ Miller et al $^{30}$ concluded in their article that to maintain the sustainability of an implemented care model in the clinical environment of the primary health care service, support from the health care organization is required. The stronger effects of the care manager organization in the second year after implementation in our study are most likely associated with the Region Västra Götaland's decision in 2017 to require all PHCCs in the region to implement the organization. The region has allocated extra resources to the PHCCs for this implementation, and by registering a special care manager code in the health care register VEGA, the PHCCs receive additional reimbursements from the region. 


\section{Methodological Considerations}

This register-based study followed the criteria of the STROBE checklist (Strengthening the reporting of observational studies in epidemiology). ${ }^{31} \mathrm{~A}$ major strength of register data is the possibility to include and handle large numbers of study objects. It also enables research on reallife outcomes as the data emerge from an everyday clinical setting. Sweden has a long tradition of collecting information in different national and regional health care registers, which is available to research after approval from an ethical committee. The use of register data from VEGA in this study enabled the inclusion of all 215 PHCCs in Region Västra Götaland which correspond to about $18 \%$ of Sweden's 1200 PHCCs. We believe that this increases the generalizability of our findings to other regional primary health care contexts in Sweden. However, extrapolation of our findings to other health care settings could be more difficult as health care systems in different countries vary. ${ }^{10}$

A possible methodological limitation important to acknowledge is that with register data, we cannot determine either the intensity or quality of treatments and visits the individual patient received. Furthermore, this is also a problem with the use of aggregated data. Aggregated data could result in information bias because of the lack of information on the individual level. ${ }^{32}$ These potential biases are not possible to control for with grouped variables. The grouped variables hinder further scrutiny of the data to distinguish variations among individual patients. However, the aim of this study was only to study the PHCCs' output concerning health care contacts and extent of psychotherapy, not how the individual patients perceived the care, as this has been studied in earlier research. ${ }^{19}$ Aggregated data also require many hours of complex data management and an understanding of which methods of analysis are best capable of handling the complexity in the correct way.

\section{Implications}

PHCC-level evaluations of comprehensive implementation of a care manager organization have not been conducted before on the possible associations with the number of health care contacts and extent of psychotherapy. In combination with our previous study in which we evaluated the organization and its association with antidepressant medication patterns ${ }^{18}$ we have shown the benefit of implementing a care manager organization based on registered data. As is shown in the results and literature, CMDs are difficult to treat, but the implementation of a care manager in PHCCs in Region Västra Götaland showed significant positive improvements in the treatment of CMDs. The analysis over time has further shown that as the implementation becomes more established, the effects are more notable. This finding implies that time is necessary for large organizational implementations to become settled into clinical practice.

We believe that the findings from the present study could be a valuable addition to the knowledge base for decision-makers and other health care officials responsible for quality development in the primary health care sector.

\section{Conclusions}

Our findings have shown that important aspects of methodological and organizational implementations in real-world primary health care are sustainability and adaptations to further development of primary health care. This evaluation of development of care in an important sector of primary health care, namely care of patients with CMD, shows that the care manager organization at PHCC level implies higher accessibility of care as well as sustainability for up to two years after implementation. As the implementation is still ongoing, future studies should continue to evaluate different effect outcomes of the care manager organization in the Swedish primary health care.

\section{Data Sharing Statement}

The datasets generated and/or analyzed during the current study are not publicly available due to Swedish legislation but are available from the corresponding author on reasonable request.

\section{Ethics Approval and Informed Consent}

Ethics approval for data extraction was obtained prior to study start by the Regional Ethical Review Board in Gothenburg, Sweden (Dnr: T566-17). All collected information was on aggregated PHCC level and, thus, no individuals could be identified and no informed consent was necessary. All methods were performed in accordance with the Declaration of Helsinki and the STROBE guidelines (Strengthening the reporting of observational studies in epidemiology). 


\section{Acknowledgments}

The authors would like to thank Mikael Kjerfve, statistician at the Department for Data and Analysis at Region Västra Götaland, for his invaluable assistance with the data extraction from VEGA, and Nashmil Arai for once again helping out with the data management. The paper has been proofread by an English native-speaking professional at Anchor English - Proofreading Service.

\section{Author Contributions}

$\mathrm{CB}$ is the principal investigator of the project. $\mathrm{CB}$ and $\mathrm{CS}$ planned the design of the study. $\mathrm{CB}, \mathrm{CS}, \mathrm{TH}$ and $\mathrm{GH}$ took part in planning the analyses. CS was the main person responsible for conducting the analyses and drafting the paper. All authors contributed to data analysis, drafting or revising the article, have agreed on the journal to which the article will be submitted, gave final approval of the version to be published, and agreed to be accountable for all aspects of the work.

\section{Funding}

This research was funded by FORTE (The Swedish Research Council for Health, Working Life and Welfare), grant number 2013-2216, and by grants from the ALF agreement, Region Västra Götaland (ALF-GBG-722441). The funding body had no role in the design of the study, in the collection, analysis, or in interpretation of data, nor in writing the manuscript.All authors were independent from the funder.

\section{Disclosure}

The authors report no conflicts of interest in this work.

\section{References}

1. GBD 2017 Disease and Injury Incidence and Prevalence Collaborators. Global, regional, and national incidence, prevalence, and years lived with disability for 354 diseases and injuries for 195 countries and territories, 1990-2017: a systematic analysis for the Global Burden of Disease Study 2017. Lancet. 2018;392 (10159):1789-1858. doi:10.1016/S0140-6736(18)32279-7

2. Steel Z, Marnane C, Iranpour C, et al. The global prevalence of common mental disorders: a systematic review and meta-analysis 1980-2013. Int $J$ Epidemiol. 2014;43(2):476-493. doi:10.1093/ije/ dyu038

3. The Swedish National Board of Health and Welfare [Socialstyrelsen]. National Guidelines for Care of Depression and Anxiety Disorders [Vård Vid Depression Och Angestsyndrom]. Socialstyrelsen; 2020.

4. Sundquist J, Ohlsson H, Sundquist K, Kendler KS. Common adult psychiatric disorders in Swedish primary care where most mental health patients are treated. BMC Psychiatry. 2017;17(1):1-9. doi:10.1186/s12888-017-1381-4
5. Lykkegaard J, Rosendal M, Brask K, Brandt L, Prior A. Prevalence of persons contacting general practice for psychological stress in Denmark. Scand J Prim Health Care. 2018;36(3):272-280. doi:10.1080/02813432.2018.1499494

6. Olsson S, Hensing G, Burström B, Löve J. Unmet need for mental healthcare in a population sample in Sweden: a cross-sectional study of inequalities based on gender, education, and country of birth. Community Ment Health J. 2021;57(3):470-481. doi:10.1007/ s10597-020-00668-7

7. NICE. Clinical guidelines: common mental health problems - identification and pathways to care; 2011. Available from: https://www. nice.org.uk/guidance/CG123/chapter/1-Guidance\#steps-2-and-3-treat ment-and-referral-for-treatment. Accessed May 14, 2020.

8. Swedish Medical Products Agency [Läkemedelsverket]. Pharmaceutical treatment of depression, anxiety syndrome and OCD amongst children and adults [Läkemedelsbehandling av depression, ångest- syndrom och tvångssyndrom hos barn och vuxna]. Inf Swedish Med Prod Agency [Information Från Läkemedelsverket Swedish]. 2016;6:2016.

9. Nieuwenhuijsen K, Verbeek JH, Neumeyer-Gromen A, Verhoeven AC, Bültmann U, Faber B. Interventions to improve return to work in depressed people. Cochrane Database Syst Rev. 2020;10:CD006237. doi:10.1002/14651858.CD006237.pub4

10. Swedish Council on Health Technology Assessment ['SBU' Statens beredning för medicinsk utvärdering]. Implementation Support for Psychiatric Evidence in Primary Care. Report 211. 2012.

11. Barkil-Oteo A. Collaborative care for depression in primary care: how psychiatry could "Troubleshoot"current treatments and practices. Yale J Biol Med. 2013;86(2):139-146.

12. Gunn J, Diggens J, Hegarty K, Blashki G. A systematic review of complex system interventions designed to increase recovery from depression in primary care. BMC Health Serv Res. 2006;6(1):1-11. doi:10.1186/1472-6963-6-88

13. Coventry PA, Hudson JL, Kontopantelis E, et al. Characteristics of effective collaborative care for treatment of depression: a systematic review and meta-regression of 74 randomised controlled trials. PLoS One. 2014;9(9):e108114. doi:10.1371/journal.pone.0108114

14. Avby G, Kjellström S, Andersson Bäck M. Tending to innovate in Swedish primary health care: a Qualitative Study. BMC Health Serv Res. 2019;19(1):42. doi:10.1186/s12913-019-3874-y

15. Richter-Sundberg L, Nyström ME, Krakau I, Sandahl C. Improving treatment of depression in primary health care: a Case Study of obstacles to perform a clinical trial designed to implement practice guidelines. Prim Health Care Res Dev. 2015;16(2):188-200. doi: $10.1017 / \mathrm{S} 1463423614000243$

16. HSL. The Swedish health and medical services act 2017:30 [HälsoOch Sjukvårdslagen 2017:30]. Sveriges Riksdag; 2017. Available from: https://www.riksdagen.se/sv/dokument-lagar/dokument/svenskforfattningssamling/halso-och-sjukvardslag_sfs-2017-30. Accessed August 30, 2021.

17. Björkelund C, Svenningsson I, Hange D, et al. Clinical effectiveness of care managers in collaborative care for patients with depression in Swedish primary health care: a pragmatic cluster randomized controlled trial. BMC Fam Pract. 2018;19(1):1-10. doi:10.1186/s12875018-0711-Z

18. Sandheimer C, Björkelund C, Hensing G, Mehlig K, Hedenrud T. Implementation of a care manager organisation and its association with antidepressant medication patterns: a Register-Based Study of primary care centres in Sweden. BMJ Open. 2021;11(3):e044959. doi:10.1136/bmjopen-2020-044959

19. Udo C, Svenningsson I, Björkelund C, Hange D, Jerlock M, Petersson E. An interview study of the care manager functionopening the door to continuity of care for patients with depression in primary care. Nurs Open. 2019;6(3):nop2.277. doi:10.1002/ nop2.277 
20. Thiébaut R, Jacqmin-Gadda H, Chêne G, Leport C, Commenges D. Bivariate linear mixed models using SAS proc MIXED. Comput Methods Programs Biomed. 2002;69(3):249-256. doi:10.1016/ s0169-2607(02)00017-2

21. Aragonès E, Caballero A, Piñol JL, López-Cortacans G. Persistence in the long term of the effects of a collaborative care programme for depression in primary care. J Affect Disord. 2014;166:36-40. doi:10.1016/j.jad.2014.05.003

22. Grypma L, Haverkamp R, Little S, Unützer J. Taking an evidence-based model of depression care from research to practice: making lemonade out of depression. Gen Hosp Psychiatry. 2006;28 (2):101-107. doi:10.1016/j.genhosppsych.2005.10.008

23. Gilbody S, Bower P, Fletcher J, Richards D, Sutton AJ. Collaborative care for depression: a cumulative meta-analysis and review of longer-term outcomes. Arch Intern Med. 2006;166(21):2314-2321. doi:10.1001/archinte.166.21.2314

24. Gilbody S, Bower P, Whitty P. Costs and consequences of enhanced primary care for depression: systematic review of randomised economic evaluations. $B r \quad J$ Psychiatry. 2006;189(4):297-308. doi:10.1192/bjp.bp.105.016006

25. Holst A, Ginter A, Björkelund C, et al. Cost-effectiveness of a care manager collaborative care programme for patients with depression in primary care: economic evaluation of a pragmatic randomised controlled study. BMJ Open. 2018;8(11):e024741. doi:10.1136/bmjopen-2018-024741

26. Celano CM, Healy B, Suarez L, et al. Cost-effectiveness of a collaborative care depression and anxiety treatment program in patients with acute cardiac illness. Value Health. 2016;19 (2):185-191. doi:10.1016/j.jval.2015.12.015
27. Grubbs KM, Cheney AM, Fortney JC, et al. The role of gender in moderating treatment outcome in collaborative care for anxiety. Psychiatr Serv. 2015;66(3):265-271. doi:10.1176/appi.ps.201400049

28. Parikh SV, Quilty LC, Ravitz P, et al. Canadian Network for Mood and Anxiety Treatments (CANMAT) 2016 clinical guidelines for the management of adults with major depressive disorder. Can J Psychiatry. 2016;61(9):524-539. doi:10.1177/0706743716659418

29. Whelan J, Love P, Pettman T, et al. Cochrane update: predicting sustainability of intervention effects in public health evidence: identifying key elements to provide guidance. J Public Health (Bangkok). 2014;36(2):347-351. doi:10.1093/pubmed/fdu027

30. Miller CJ, Grogan-Kaylor A, Perron BE, Kilbourne AM, Woltmann E, Bauer MS. Collaborative chronic care models for mental health conditions: cumulative meta-analysis and metaregression to guide future research and implementation. Med Care. 2013;51 (10):922-930. doi:10.1097/MLR.0b013e3182a3e4c4

31. STROBE. STROBE Statement. Strengthening the reporting of observational studies in epidemiology; 2009. Available from: https:/www. strobe-statement.org/index.php?id=available-checklists. Accessed March 11, 2021.

32. Morgenstern H. Ecologic studies in epidemiology: concepts, principles, and methods. Annu Rev Public Health. 1995;16(1):61-81. doi:10.1146/annurev.publhealth.16.1.61
International Journal of General Medicine

\section{Publish your work in this journal}

The International Journal of General Medicine is an international, peer-reviewed open-access journal that focuses on general and internal medicine, pathogenesis, epidemiology, diagnosis, monitoring and treatment protocols. The journal is characterized by the rapid reporting of reviews, original research and clinical studies

\section{Dovepress}

across all disease areas. The manuscript management system is completely online and includes a very quick and fair peer-review system, which is all easy to use. Visit http://www.dovepress.com/ testimonials.php to read real quotes from published authors. 